\title{
A EDUCAÇÃO COMO COMMODITY: A POLÍTICA DE ORGANISMOS INTERNACIONAIS
}

\author{
Eduard Angelo Bendrath
}

Mestrando do Programa de Pós-Graduação em Educação. Faculdade de Ciências e Tecnologia. FCT/UNESP. Bolsista da Fundação de Amparo à Pesquisa do Estado de São Paulo - FAPESP

\section{RESUMO}

O presente artigo tem por finalidade discutir o panorama global da Educação, visto do prisma dos organismos multilaterais de influência direta nas políticas regionais, em especial de países em desenvolvimento. O conceito de Educação como setor comercial e abertura de investimento estrangeiro, na área de Educação, pela OMC, Banco Mundial e FMI, corresponde a uma mudança abrupta nas relações educativas e fixa as bases para uma exclusão educacional cada vez mais acentuada, nos países em desenvolvimento. A atuação da UNESCO e sua representação legítima como autoridade internacional, em parceria com o Banco Mundial, colocam em dúvida os reais interesses sobre os objetivos de ambas as instituições, no cenário mundial e as consequências diretas dessa relação, no campo da Educação. E o que podemos esperar das políticas educacionais pautadas em acordos com agências financiadoras internacionais? A Educação como commodity será o futuro?

Palavras-chave: Políticas Educacionais; FMI; Banco Mundial; OMC; UNESCO.

EDUCATION AS COMMODITY: A POLICY OF INTERNATIONAL ORGANIZATIONS

\begin{abstract}
This article aims to discuss the overall picture of education as the prism of the multilateral organizations of direct influence on regional policies, especially in developing countries. The concept of education as a business sector and opening up foreign investment in education by the WTO, World Bank and IMF, is an abrupt change in educational relations and set the foundations for an educational exclusion increasingly in developing countries. The role of UNESCO and its representation as a legitimate international authority in partnership with the World Bank put in doubt the real interests of the goals of both institutions in the world and the direct consequences of this relationship in the education field. And what can we expect of education policies based on international agreements with funding agencies? Education as commodity will be the future?
\end{abstract}

Key words: Educational Policy; IMF; World Bank; WTO; UNESCO. 


\section{INTRODUÇÃO}

Antes de iniciar as discussões sobre Educação, em uma esfera global, é importante destacar que concebo como Organismos Multilaterais as Instituições Privadas ou Não Governamentais, sejam elas de ordem financeira ou não, de origem estrangeira, não subordinadas ao Estado. O presente artigo não tem por finalidade criticar decisões estatais na tomada de empréstimos ou implantação de projetos financiados, mas fazer uma discussão preliminar acerca do campo da Educação, no novo cenário mundial, suas possibilidades e avanços, tendo como parâmetro as políticas de Organismos Multilaterais, em especial, o Banco Mundial, a Organização Mundial do Comércio (OMC), o Fundo Monetário Internacional (FMI) e a Organização das Nações Unidas para a Educação, a Ciência e a Cultura (UNESCO).

Quando pensamos em políticas internacionais, logo pensamos em propostas e acordos entre países, com objetivos específicos, sejam eles militares, comerciais ou diplomáticos. Decisões governamentais servem de base para a elaboração de políticas públicas locais, entre as quais a educacional. Nas últimas décadas, temos acompanhado um crescente interesse de órgãos internacionais no gerenciamento e elaboração de propostas na área da Educação, principalmente para os países em desenvolvimento. Desde o pósguerra (1945), instituições como o Banco Mundial, criado para auxiliar na reconstrução e financiamento dos países afetados pelo conflito, contribuem para o restabelecimento do panorama global, com auxílio financeiro e propostas de regulação setorial. De 1947 a 1957, 0,4\% dos empréstimos (TOMMASI, 1996, p. 20) do Banco Mundial eram destinados aos setores sociais; esse montante subiu para 3,7\%, de 1958 a 1968, e para
12,8\%, entre 1969 e 1979, mas é a partir da década de 1980 que os projetos nas áreas sociais ganham força dentro da instituição, com o objetivo de reduzir a pobreza e a desigualdade entre os povos.

Para Haddad (2008), a década de 1980 consistiu em um período importante de reorientação do papel e das políticas, tanto do Banco Mundial quanto dos demais organismos multilaterais de financiamento, como o Fundo Monetário Internacional (FMI). Propostas de adequações econômicas eram impostas aos países em desenvolvimento, e muitas dessas regras afetavam a área educacional. Segundo Silva (2002, p. 26), uma dessas adequações econômicas, conhecida como Consenso de Washington, tratava de uma regra de 10 medidas de impacto imediato na regulação econômica:

$\begin{array}{ll}\text { - } & \text { Disciplina Fiscal } \\ \text { - } & \text { Redução dos Gastos Públicos } \\ \text { - } & \text { Jeforma Tributária } \\ \text { - } & \text { Câmbio de Mercado } \\ \text { - } & \text { Abertura Comercial } \\ \text { - } & \text { Investimento Estrangeiro } \\ \text { - } & \text { Privatização das Estatais } \\ \text { - } & \text { Desregulamentação } \\ \text { - } & \text { Direito à propriedade }\end{array}$

Dentro desse princípio, Barroso (2005) acredita que o conceito de regulação está igualmente associado ao controle de elementos autônomos, porém interdependentes. Nesse sentido, é usado em Economia, por exemplo, para identificar a intervenção de instâncias com autoridade legítima (normalmente estatais) para orientarem e coordenarem a ação dos agentes econômicos (a regulação dos preços, a regulação do comércio, da energia etc.). A rigidez desse controle econômico reduziu os investimentos em Educação, priorizando setores de infraestrutura e 
indústria. Contudo, os financiamentos para setores sociais era uma demanda mundial e nem as diretrizes internas definidas pelo Banco Mundial para a concessão de empréstimos garantiam um bom retorno para a instituição. Soares (1996, p. 26) destaca que o Relatório Wapenhans, do Banco Mundial, em 1992, mostra que $37,5 \%$ dos projetos analisados fracassaram, enquanto $78 \%$ não seguiram as diretrizes internas definidas pelo banco; com tal panorama, o Banco Mundial fez sérias recomendações para a nova concessão de empréstimos, o que, para Soares (1996, p. 26-27), teria como objetivo garantir o retorno previsto:

- Realização de uma avaliação das consequências reais dos projetos financiados, após a conclusão;

- Garantia da participação adequada dos tomadores de empréstimos e da população afetada, em todas as fases de preparação e realização dos projetos;

- Melhoria da qualidade dos empréstimos realizados, evitando a aprovação de projetos simplesmente pelas "pressões para emprestar";

- Mudança da característica da instituição, onde somente contam critérios econômicos e financeiros, pontuando-se a questão central - a contradição entre a instituição financeira, que é o Banco, e a agência de desenvolvimento, que deveria ser.

Com o fracasso de muitos projetos educacionais financiados, as mudanças na economia global e o incremento de políticas neoliberais, seguidas com exatidão, a Educação começou a ter um novo papel, dentro dos organismos internacionais, passando a ser vista não apenas como um direito e instrumento de redução da pobreza, mas como uma maneira de formação do capital humano (SOARES, 1996).

As políticas sociais estão orientadas para dar continuidade ao processo de desenvolvimento humano que ocorreu apesar da falência do processo de industrialização e desenvolvimento econômico. Sua bandeira é investir os recursos públicos "nas pessoas", garantindo que todos tenham um acesso mínimo de educação, saúde, alimentação, saneamento e habitação, bem como às condições para aumentar a expectativa de vida e para alcançar uma distribuição mais eqüitativa das oportunidades. Estas políticas não incluem uma definição sobre como conseguir que o "capital humano" seja algo mais do que um recurso de baixo custo para o capital, e de fato promovem a equidade à custa do empobrecimento dos setores médios urbanos, sem afetar as camadas de alta renda. (CORAGGIO, 1996, p. 77).

\section{A Educação no novo panorama Mundial}

Mediante a nova oportunidade e uma globalização cada vez maior, os padrões educacionais principiaram a ter importância, no contexto mundial, uma vez que a formação do capital humano é vital para o início do desenvolvimento local e, consequentemente, para uma abertura maior da economia. Tratar a Educação como direito universal ou como serviço passou a ser a dúvida e a questão contraditória, nessa ampliação dos horizontes globalizados: como oferecer uma Educação básica aos mais pobres e ter, ao mesmo tempo, a responsabilidade da formação do "capital humano"?

A influência dos Organismos Internacionais cresceu, entre os países com os quais mantinham acordos, impondo adequações necessárias à 
formação humana e ao desenvolvimento. Todavia, divergências entre tais organismos eram recorrentes e advinham da necessidade das agências financiadoras de cobrar resultados práticos, para concessão de empréstimos, e de organismos humanitários, que propugnam por uma política de Educação para todos.

Essa influência muitas vezes ditou e dita as políticas públicas de Estado, sempre pautadas em metas pré-estabelecidas, com objetivos claros e retorno previsto para o investimento feito, mesmo que, muitas vezes, esse investimento seja apenas de forma estrutural, através de cooperação técnica na implantação de projetos - e não financeira, com concessão direta de crédito.

Muitos projetos de Educação, na área básica, denominada Educação Para Todos (EPT), foram igualmente apoiados por instituições financeiras, mostrando um crescente interesse desses organismos na hegemonia de implantação, financiamento e apropriação dos resultados oriundos dessa relação.

\begin{abstract}
Apesar da Organização das Nações Unidas para Educação e Cultura (UNESCO) ser por excelência a principal instituição multilateral responsável pela implementação da estratégia de Educação Para Todos, o Banco Mundial vem tendo um papel mais determinante, trazendo reflexos consideráveis para todo o modo como a cooperação internacional concebe a educação e nos projetos apoiados. (FIORI, 2001, p. 89-90, apud HADDAD, 2008, p. 22).
\end{abstract}

Mesmo a própria UNESCO, considerada, por excelência, a instituição mundial responsável pela Educação, na Organização das Nações Unidas (ONU), tem, como suporte estrutural de seu capital financiador, organismos multilaterais desde a década de 1950, o que certamente modificou o panorama global da Educação, tendo em vista o conflito de interesses entre instituições.

Os reordenamentos econômicopolíticos e os avanços tecnológicos desde a segunda metade dos anos 1950 anunciam um novo momento nas relações mundiais $\mathrm{e}$ configuram um contexto em que se ampliam os recursos financeiros da UNESCO, tanto em relação ao orçamento ordinário como aos recursos extra-orçamentários provenientes de outras fontes, incluindo os organismos privados. (EVANGELISTA, 1999, p. 44).

A UNESCO utiliza toda sua competência técnica na elaboração e acompanhamento do setor educacional dos países mais necessitados, trabalhando ainda com metas e prazos a serem cumpridos; seu atual patamar estabelece metas para 2015, pautadas no Relatório de Monitoramento Global de Educação para Todos 2008 (UNESCO. EDUCACION...), em que o tema "Educação para Todos até 2015: alcançaremos esta meta?" - faz referência direta à erradicação da pobreza, por meio da Educação.

Podemos pensar a Educação concebida como direito universal ou como instrumento de melhoria da qualidade de vida, todavia, o que é importante e necessário compreender é o porquê as ligações da Educação com o mercado, nos dias atuais, se fazem tão presentes na medida em que a necessidade econômica aumenta. Em um primeiro momento, podemos acreditar que a Educação é imprescindível, na mesma proporção com que a qualificação profissional é cada dia mais exigida, na ocupação dos postos de trabalho, porém, de uma forma indireta, é possível verificar que a premência de mão-de-obra mais qualificada surge da necessidade da ocupação do maior número de postos de trabalho, sejam eles quais forem, para o "aquecimento da economia interna". 
Cabe, é verdade, ressaltar que as políticas educacionais, ao longo dos anos, nascem da UNESCO (a representante dos direitos educacionais e culturais legítimos) isentas de interesses obscuros; contudo, essa relação não é expressa de forma autônoma e, frequentemente, as políticas são direcionadas por interesses externos ao processo educacional, conforme se pode notar, por exemplo, na existência de trabalhos da UNESCO realizados em cooperação com outras agências internacionais, em especial o Banco Mundial. Tal cooperação teve início no pós-guerra, com a liberação de recursos financeiros por parte do banco, perpetuando-se até hoje ${ }^{1}$ :

Novos recursos, destinados até então exclusivamente a projetos de infraestrutura material, possibilitam uma ampliação da capacidade de atuação da UNESCO nesse período, em que o Banco Mundial se volta para as reformas das estruturas educacionais [...] a inclusão da educação como fator de desenvolvimento nos objetivos do banco intensifica a busca de racionalização das estruturas educacionais. (EVANGELISTA, 1999, p. 45).

Conceber a Educação como cultura e processo valorativo, na formação do indivíduo, parece estar em segundo plano, enquanto objetivos macroeconômicos favorecem cada vez mais uma política neoliberal do Estado, apoiados e fortalecidos por organismos multilaterais. O discurso atual do fortalecimento das ações, na Educação básica e na erradicação do analfabetismo da UNESCO, vai de encontro às propostas, por exemplo, do Banco Mundial, o qual, segundo Torres (1996, p. 131), estimula os países a concentrar os recursos públicos na Educação

\footnotetext{
${ }^{1}$ Site oficial da UNESCO no Brasil, onde há referência à atuação em conjunto com o Banco Mundial e outros Organismos Internacionais. Disponível

http://www.brasilia.unesco.org/comunidades/nacoesunidas. Acesso em: 13 mar. 2009.
}

básica, que é responsável, comparativamente, pelos maiores benefícios sociais e econômicos ${ }^{2}$. É possível verificar que existem estreitas e íntimas ligações entre o desenvolvimento educacional e social e a regulação econômica, para os Organismos Multilaterais.

\section{O Comércio de Educação}

Tratar a Educação como um serviço parece ser a tônica dos novos rumos que veremos em um futuro não muito distante. Com a criação da Organização Mundial do Comércio (OMC), em 1995, substituindo o antigo Acordo Geral de Tarifas Aduaneiras e Comércio (GATT, em inglês), alguns novos setores foram encampados pela entidade, cujo objetivo principal é regular o comércio exterior entre os países, estabelecendo regras gerais e sendo fórum de apelações para casos de disputa comercial entre seus membros.

A OMC é uma organização multilateral, responsável pelo estabelecimento do fluxo comercial mundial e, como as demais instituições internacionais, seu objetivo é fixar regras e procedimentos que regulem o comportamento dos Estados (CAMPOS, 2008). O estabelecimento de acordos com a OMC implica ao país o aceite de suas condições, baseados na regra do livre acesso ao comércio.

A concepção de Educação para a OMC situa-se no campo da prestação de serviços e, como tal, deve ser explorada além das fronteiras, com a abertura dos mercados. Tratar a Educação como mercadoria seria considerar o acesso restrito a quem detém o capital para comprá-la, excluindo as populações mais pobres e concentrando as regras do jogo nas elites dominantes.

As normas da Organização Mundial do Comércio afetam os direitos humanos principalmente ao

\footnotetext{
2. Grifo meu.
} 
restringir a capacidade dos governos de regulamentar ou tomar outras medidas para promover o respeito a esses direitos em seus países. Na verdade, ao promover o "livre-comércio", tanto os acordos da OMC quanto os bilaterais buscam afastar de uma vez quaisquer possíveis interferências de regulamentação no livre fluxo de bens e serviços, limitando assim a capacidade dos governos de adotar regras favoráveis ao desenvolvimento, à proteção ambiental e à defesa dos setores vulneráveis da sociedade. (DOMMEN, 2005, p. 10).

Desde a Rodada do Uruguai, em 1995, a OMC estabeleceu o Acordo Geral de Comércio de Serviços (GATS em inglês), baseado nas negociações feitas na época. O GATS representa uma gama de áreas setoriais de serviços, a saber: Comércio; Comunicação; Construção e Engenharia; Distribuição; Educação; Meio Ambiente; Serviços Financeiros; Saúde; Turismo e Viagens; Lazer; Cultura e Esporte e Transporte.

Silva, Gonzalez e Brugier (2008), afirmam que as negociações do GATS seguem um quadro jurídico comum a todos os acordos da OMC, em particular a cláusula da Nação Mais Favorecida e o Trato Nacional, mas também algumas disciplinas particulares adaptadas ao setor de serviços, como a mudança das regras de aduana para regras de acesso ao mercado. A cláusula da Nação Mais Favorecida estabelece que um país que abrir seu mercado para outro, em determinado setor, deve estender esse privilégio a todos os países participantes do acordo; já o Trato Nacional proíbe a concessão de privilégios a empresas nacionais, discriminando as estrangeiras, por meio, por exemplo, de incentivos fiscais.

Esse discurso contraria a Declaração Mundial de Educação para Todos (JOMTIEN, 1990) e a Declaração Mundial dos Direitos Humanos, que concebem a Educação como direito universal. Fundamentados nessas premissas, muitos países ainda não aderiram por completo ao GATS. Um exemplo claro é o Brasil, cuja Constituição proíbe que a Educação básica seja tratada como serviço, de sorte que o Estado possui o direito, o dever e a responsabilidade sobre essa questão.

O Brasil adotou uma posição contrária [...] com o argumento de que não parecem levar devidamente em conta a necessidade de respeitar a arquitetura e as flexibilidades construídas no GATS [...], o Brasil ressalta que as propostas de benchmarks (sic) desrespeitam o artigo XIX do GATS, que estipula que o processo de liberalização deve respeitar devidamente os objetivos de política nacional e o nível de desenvolvimento de cada membro. (SILVA; GONZALEZ; BRUGIER, 2008, p. 93).

A regulação internacional da Educação, por meio da OMC e do GATS, interfere diretamente nas ações de Estado, no sentido de que este passa a não possuir o "poder" do desenvolvimento humano de seu povo, contribuindo para uma crise de identidade na formação do indivíduo, nativo de determinado país e com educação importada.

Dentro das negociações do GATS, Silva, Gonzalez e Brugier (2008) especificam as áreas as quais a OMC elege como setores da Educação abertos a negociações internacionais:

- Educação Primária (Pré-Escola, primeiro ciclo do Ensino Fundamental)

- Educação Secundária (segundo ciclo do Ensino Fundamental, Ensino Técnico Vocacional, Educação para deficientes)

- Educação Superior (Universidades e escolas profissionalizantes especializadas, Ensino Técnico e 
Vocacional de nível póssecundário)

- Educação de Adultos (serviços não ministrados em Universidades e escolas normais, programas de alfabetização, entre outros)

- Outros Setores (qualquer serviço educacional não mencionado, exceto os de lazer)

A regra de liberalização dos setores de comércio, segundo o GATS (SILVA; GONZALEZ; BRUGIER, 2008, p. 91), são estabelecidas por quatro modos de operação, os quais discriminam a natureza das transações e o fornecimento, no caso, da prestação de serviços. São elas:

- Modo 1 - Comércio Transfronteiriço - o serviço cruza a fronteira e é oferecido em outro país.

- Modo 2 - Consumo no Exterior - o consumidor cruza a fronteira para consumir fora do país.

- Modo 3 - Presença Comercial - o investimento cruza as fronteiras e se estabelece no país estrangeiro.

- Modo 4 - Movimento Temporário de Pessoas Físicas - o fornecedor cruza as fronteiras como pessoa física.

O quadro de distribuição da Educação, para a OMC, abre praticamente todos os setores educacionais para investimento estrangeiro; neste caso, países em desenvolvimento seriam os grandes alvos para possíveis negócios, teriam um mercado repleto de setores em déficit, com ampla possibilidade de acordos. Diante dessa tendência, países como os Estados Unidos e a Austrália, além dos membros da União Européia, lideram a iniciativa no avanço das negociações do GATS na OMC.
Mesmo com pressões a favor da liberação do comércio, nesse setor, ainda são nítidos os problemas a serem enfrentados, em caso de uma abertura mundial do comércio na área da Educação; as principais ainda dizem respeito à validação e expedição de diplomas, monopólio estatal, dificuldade de recrutamento de professores estrangeiros, entre outras.

A OMC, por sua vez, não reconhece a prerrogativa dos países em decidir sobre os padrões de qualidade $\mathrm{e}$ aceitabilidade da educação disponibilizada a seus estudantes. Ao contrário, afirma que a solução é o estabelecimento de "acordos" internacionais para garantir a aceitação dos diplomas estrangeiros. (HADDAD; GRACIANO, 2004, p. 73).

A questão é quais benefícios a abertura desse setor para a comercialização mundial traria para os países em desenvolvimento. Uma maior oferta nem sempre pode representar o melhor negócio. A maior preocupação seria o Modo 3 de operação do GATS; em países com grande dificuldade no setor educacional, a economia acompanha o mesmo ritmo e a necessidade de investimento estrangeiro se resume à Educação primária e de adultos (no modelo de alfabetização e qualificação profissional), setores em larga escala operados internacionalmente pelo Banco Mundial e UNESCO. A opção poderia ser, por conseguinte, a terceirização dos serviços estatais da área da Educação para empresas estrangeiras, tendo em vista que as operações do Banco Mundial e da UNESCO são localizadas, voltadas em sua grande parte para projetos específicos; portanto, caberia a cada país tal decisão, que, no caso, acarretaria a descentralização do monopólio estatal e a limitação do controle setorial. 
Os problemas parecem não ser poucos, para uma liberação completa, na OMC, porém o primeiro passo foi dado, de maneira que as negociações estão abertas.

\section{O objetivo EPT: Educação Para Todos}

"Reunidos em Dakar em Abril de 2000, nós, participantes do Fórum Mundial de Educação, nos comprometemos a alcançar os objetivos e as metas de Educação Para Todos (EPT), para cada cidadão e cada sociedade" (UNESCO, 2001, p. 08).

De um lado, temos a Educação vista como um serviço a ser comercializado; de outro, temos a visão de uma Educação que deve ser para todos. $\mathrm{Na}$ verdade, tais cenários fazem parte de uma nova discussão mundial da área, em que objetivos e interesses se cruzam.

O compromisso de Dakar, firmado pelos países participantes do Fórum Mundial de Educação, traça alguns parâmetros a serem seguidos pelas nações, com alguns objetivos específicos. Tais objetivos englobam seis metas a serem cumpridas.

- Educação na primeira infância

- Universalização da Educação primária

- Aprendizagens de jovens e adultos

- Alfabetização de adultos

- Paridade e Igualdade de gênero

- Qualidade da Educação

Com finalidades definidas, a intenção é a de ampliar e fortalecer a Educação, principalmente nos países mais pobres, onde as condições de vida são precárias e o acesso à Educação é praticamente inexistente.

Dentre as ações apontadas pela UNESCO (2001, p. 10), está a afirmação de que a comunidade dará andamento a esse compromisso coletivo, desenvolvendo imediatamente uma iniciativa global com vistas a desenvolver estratégias e mobilizar os recursos necessários para providenciar apoio efetivo aos esforços nacionais.

O relatório de Dakar preconiza, ainda, que alguns avanços já estão sendo conseguidos e que as metas estabelecidas são plenamente atingíveis, mas salienta que deve haver um compromisso mundial com a Educação, a fim de que ela se torne realmente direito universal na constituição do indivíduo. O desafio essencial é o de assegurar que a visão ampla da Educação Para Todos como conceito inclusivo se reflita nas políticas dos governos nacionais e dos órgãos financiadores (UNESCO 2001, p. 16).

Com uma grande amplitude de ações a serem desenvolvidas, em países com grandes necessidades, e a dificuldade de estabelecimento de projetos educacionais pelos países em questão, o Banco Mundial e o FMI lançaram, em 2002, a Fast-Track Iniciative, aqui denominada Iniciativa Via Rápida (IVR), com o intuito de acelerar o desenvolvimento educacional, de acordo com as metas do milênio (JOMTIEN, 1990).

Silva, Azzi e Bock (2008) enfatizam que, para se tornarem aptos a solicitar recursos para a IVR, os países de baixo rendimento passam por um processo de análise rigoroso, condicionado a processos relacionados ao $\mathrm{FMI}$ e ao Banco Mundial. Para obter o endosso da IVR, o país deve antes receber aprovação de um documento que apresenta sua estratégia de redução da pobreza.

Mesmo com dificuldades estruturais, os países que submetem acordos ao IVR necessitam de pareceres dos órgãos financiadores, como condição para a concessão do valor emprestado, de modo que a dificuldade econômica não significa maior chance de empréstimo, porém é necessário, 
antes de tudo, estar na lista de 18 países indicados inicialmente para receber concessões da IVR. Atualmente, 15 países integram o bloco de beneficiários da IVR: Burquina Faso, Guiné-Bissau, Honduras, Mauritânia, Nicarágua, Nigéria, Etiópia, Gâmbia, Gana, Madagascar, Moldova, Moçambique, Vietnam e lêmen.

A IVR é um projeto amplo, que contempla a proposta das metas do milênio fixadas em Jomtien, em 1990, as quais ainda possuem grandes ligações e praticamente serviram de eixo para a elaboração, dez anos mais tarde, das metas de Dakar, em 2000.

Apesar de contemplar uma proposta adequada às necessidades locais, a relação mais uma vez se constrói dentro de um padrão econômico incompatível com os preceitos educacionais que se pretende atingir, uma vez que a hegemonia dos setores financeiros sobre as políticas educacionais compromete até mesmo as metas da Educação Para Todos.

Os governos precisam explorar de maneira mais ativa os modos alternativos e inovadores de aumentar os recursos disponíveis para sustentar a Educação Para Todos (EPT) e para desenvolver estratégias claramente definidas para atingir as metas da EPT, pelas quais assumam domínio real e permanente. $O$ perdão de dívidas para os países mais pobres continua inadequado [...] (UNESCO 2001, p. 17).

A UNESCO adota a política de desenvolvimento educacional dupla, tanto oferecendo, através de suas conferências, ${ }^{3}$ uma visão de Educação igualitária e de direito universal, quanto atuando em cooperação com organismos internacionais financiadores, com objetivos capitalistas.

\footnotetext{
${ }^{3}$ Ver UNESCO - Conferência Mundial de Educação Jomtien (1990) e UNESCO - Compromisso de Dacar (2000).
}

Muitos dos acordos fechados entre organismos multilaterais e países em desenvolvimento são realizados sem uma consulta prévia aos atores envolvidos e beneficiários em questão, comprometendo em muito a implantação de tais projetos, tendo em vista que um dos principais fatores do sucesso educacional, a gestão participativa, não é levada em consideração.

A rigidez na implantação de tais projetos é outro ponto a ser debatido, porque a flexibilidade para possíveis correções, no decorrer do tempo, somente é autorizada mediante análise das agências financiadoras, o que gera dificuldade no gerenciamento e modificações necessárias, durante o transcorrer do processo de implantação e desenvolvimento.

\section{O Brasil no Centro do Furacão}

Desde o Plano Real ${ }^{4}$ e a melhora e consolidação da economia, o Brasil se tornou um país interessante para investimento estrangeiro. A mudança dos planos econômicos trouxe também a necessidade de rever conceitos e políticas públicas educacionais. Com a segurança de uma economia mais confiante e forte, com um grande mercado em expansão, o investimento estrangeiro de organismos multilaterais se tornou maior, à medida que as necessidades educacionais também cresceram. O foco na Educação básica e a diminuição do analfabetismo se tornaram o centro das novas propostas, enquanto avaliações externas da Educação eram aprimoradas e implementadas, pelo Governo Federal (SAEB).

Tais medidas fortaleceram as influências diretas de uma política internacional. Nessa perspectiva, Silva (2003, p. 296) destaca de que forma o Banco Mundial focalizou como prioridade a Educação Básica, e como se deu sua indução, na

\footnotetext{
4. Governo Itamar Franco (1992-1994).
} 
criação, em 1996, do Fundo de Manutenção e Desenvolvimento da Educação Básica (FUNDEB), seguindo uma política de avaliações externas que prioriza os resultados e rendimentos definidos a priori pelo Banco, desconsiderando outros importantes elementos do processo ensinoaprendizagem. Tais medidas estão sendo cada vez mais implementadas, em especial pela Secretaria de Educação de São Paulo, que, em sua nova proposta educacional, segue a linha de indicações dos organismos multilaterais, onde se deve focalizar o rendimento de alunos e professores, baseado em metas pré-estabelecidas(SÃO PAULO, 2008. (IDESP, SARESP), e a instituição de bonificação por desempenho docente (resultado atrelado às metas pré-estabelecidas), ao invés de reajustar o piso salarial da categoria. Nesses aspectos, o governo paulista vai ao encontro das orientações do Banco Mundial, que questiona o pressuposto de que o aumento do salário dos professores bem como a redução de alunos por sala de aula se traduz em melhora da qualidade de ensino (HADDAD, 2008. p. 27).

Essa política pública do setor da Educação paulista não é única e significa que políticas partidárias não são resultados de acordos únicos com Organismos Multilaterais. O próprio Governo Federal adota parâmetros semelhantes, na condução de suas ações. O Brasil, em 2005, possuía 53 projetos em execução financiados pelo Banco Mundial (HADDAD, 2008. p. 30), totalizando quase US $\$ 5$ bilhões em recursos. Atualmente, o principal eixo que estrutura a relação entre Governo Federal e Banco Mundial é o FUNDEB, criado em 1996, com o nome de FUNDEF, contando com a base dos pilares do Banco para a Educação, que "sugere" a aplicação dos recursos na Educação básica, gerando um desequilíbrio entre os demais setores educacionais.

\section{CONSIDERAÇÕES FINAIS}

Os aspectos destacados no presente texto permitem-nos inferir que a atuação dos Organismos Multilaterais se faz em sua grande parte através de suas influências políticas nos Estados em que ingressam. Os empréstimos feitos são cobrados não apenas financeiramente, mas em sua ordem político-estrutural, pois são cobrados resultados práticos dessa aplicação no retorno previsto na economia, seu grande objetivo. É possível perceber que as relações educacionais propriamente ditas, como a relação educador-educando, fatores familiares entre outros, não são considerados pontos críticos pelas políticas educacionais de tais organismos, e mesmo com tais críticas, seus ajustes são seguidos cegamente como regras infalíveis para a solução da Educação. A mercantilização ou a Educação como commodity apenas veio reforçar a nova tendência de objetivos econômicos ante ao social, negócio versus cultural, e nesse sentido é compreendida apenas como um fator de fortalecimento das ações de tais organismos na influência da aplicação de suas medidas em países em desenvolvimento.

É importante salientar que a Educação, enquanto serviço, implantada dentro do setor de comércio da OMC, terá como consequência direta a modificação das estruturas legais dos países, que, desde a teoria econômica de Keynes, amplamente difundida na década de 1930 e no pós-guerra, trata, entre outros setores, a Educação como responsabilidade e dever do Estado, contrariando todos os preceitos e postulados do neoliberalismo contemporâneo.

Bianchetti (2001) destaca que o modelo econômico neoliberal não tem como objetivo criar soluções ou propor estratégias de desenvolvimento global, mas apenas redistribuir as riquezas. O que podemos prever, nesse sentido, é uma adequação 
do modelo educacional à lógica de mercado, garantindo assim o acesso irrestrito da elite dominante aos bens e produtos educacionais e, da mesma maneira, acentuando as desigualdades, ao excluir grande parte da população de baixa renda de um direito até então universal: a Educação.

A necessidade de uma articulação do poder do Estado com a iniciativa de tais Organismos é plausível e até certo ponto aceitável, em virtude da grande dificuldade de recursos financeiros $\mathrm{e}$ gerenciamento da máquina pública; porém, é necessário compreender que tais medidas devem ser adotadas dentro da realidade, levando-se em conta as particularidades de cada setor ao qual se destina a aplicação de tais recursos. A rigidez e o controle econômico-burocrático de medidas educacionais não são, nem nunca foram, soluções para a melhoria da qualidade da Educação, no Brasil. Por conseguinte, é importante que se tenha uma participação efetiva de todos os setores: Organismo Financiador, Estado e População, com o objetivo de dinamizar a aplicação de recursos, viabilizando as estruturações necessárias e articulando a necessidade local com o interesse estatal.

Contudo, deve-se salientar que o possível controle setorial e burocrático, realizado por organismos multilaterais, retira do Estado seu poder de decisão sobre instâncias importantes na fortificação e consolidação de suas ações, deixando-o à mercê de políticas internacionais e interesses estrangeiros.

\section{REFERÊNCIAS}

BARROSO, J. O Estado, a educação e a regulação das políticas públicas. Educ. Soc., Campinas, v. 26, n. 92, 2005. Disponível em: $<$ http://www.scielo.br/scielo.php?script=sci_arttext\&
pid=S0101-73302005000300002\&lng=pt\&nrm=iso $>$. Acesso em: 22 jun. 2008.

BIANCHETTI, R. G. Modelo Neoliberal e Políticas Educacionais. 3.ed. São Paulo: Cortez, 2001. $118 \mathrm{p}$.

CAMPOS, T. L. C. Uma avaliação do efeito institucional sobre o comportamento dos Estados membros da OMC a partir da análise de convergência e divergência nas negociações do Gatt, Gats e Trips. Revista Brasileira de Política Internacional, v. 51, n. 2, p. 117-135, 2008. Disponível em: http://www.scielo.br/scielo.php?script=sci_arttext\&pi $d=S 0034-73292008000200008 \&$ lng=pt\&nrm=iso.

Acesso em: 13 mar. 2009.

CORAGGIO, J. L. Propostas do Banco Mundial para a educação: sentido oculto ou problemas de concepção? In; TOMMASI, L. de et al. O Banco Mundial e as Políticas Educacionais. São Paulo: Cortez, 1996. p. 75-123.

DOMMEN, C. Comércio e Direitos Humanos: Rumo à Coerência. Revista Internacional de Direitos Humanos, São Paulo, v. 2, n. 2, p. 6-25, 2005.

EVANGELISTA, E. G. dos S. A UNESCO e o mundo da cultura. Campinas, SP: [s.e.], 1999. $222 \mathrm{p}$.

FIORI, J. L. O "pós-consenso de Washington". In: HADDAD, S. Banco Mundial, OMC e FMI: o impacto nas políticas educacionais. São Paulo: Cortez, 2008. 214 p.

HADDAD, S. Banco Mundial, OMC e FMI: o impacto nas políticas educacionais. São Paulo: Cortez, 2008. $214 \mathrm{p}$.

HADDAD, S.; GRACIANO, M. Educação: direito universal ou mercado em expansão. Perspec., 
São Paulo, v. 18, n. 3, 2004. Disponível em: $<$ http://www.scielo.br/scielo.php?script=sci_arttext\& pid=S0102-88392004000300008\&lng=pt\&nrm=iso $>$. Acesso em: 22 jun. 2008.

SILVA, C. C.; GONZALEZ, M.; BRUGIER, Y. S. OMC em Foco: a comercialização da educação na América Latina. In: HADDAD, Sérgio. Banco Mundial, OMC e FMI: o impacto nas políticas educacionais. São Paulo: Cortez, 2008. p. 89-143.

SILVA, C. C.; AZZI, D.; BOCK, R. Banco Mundial em foco: sua atuação na educação brasileira e na dos países que integram a Iniciativa Via Rápida na América Latina. In: HADDAD, Sérgio. Banco Mundial, OMC e FMI: o impacto nas políticas educacionais. São Paulo: Cortez, 2008. p. 17-86.

SÃO PAULO (Estado). Secretaria de Estado da Educação. Programa de Qualidade da Escola. Disponível em: http://idesp.edunet.sp.gov.br/. Acesso em: 22 jun. 2008.

SILVA, M. A. da. Do projeto político do Banco Mundial ao projeto político-pedagógico da escola pública brasileira. Cad. CEDES, Campinas, v. 23, n. 61, 2003. Disponível em: <http://www.scielo.br/scielo.php?script=sci_arttext\& pid=S0101-32622003006100003\&lng=pt\&nrm=iso > . Acesso em: 22 jun. 2008.

SILVA, M. A. da. Intervenção e Consentimento: a política educacional do Banco Mundial. Campinas, SP: Autores Associados; São Paulo: FAPESP, 2002. $224 \mathrm{p}$.

SOARES, M. C. C. Banco Mundial: políticas e reformas. In: TOMMASI, L. de et al. O Banco Mundial e as Políticas Educacionais. São Paulo: Cortez, 1996. p. 15-39.

TOMMASI, L. de et al. O Banco Mundial e as Políticas Educacionais. São Paulo: Cortez, 1996. $279 \mathrm{p}$.
TORRES, R. M. Melhorar a qualidade da educação básica? As estratégias do Banco Mundial. In: TOMMASI, L. de et al. O Banco Mundial e as Políticas Educacionais. São Paulo: Cortez, 1996. p. 125-193.

UNESCO. Educação Para Todos: o compromisso de Dakar. Brasília, DF: Ação Educativa, 2001. 70 p.

UNESCO. Informe del Seguimiento de la EPT en el mundo: Educación para Todos en 2015: Alcanzaremos la meta? Disponível em: $<$ http://unesdoc.unesco.org/images/0015/001548/15 4820s.pdf >. Acesso em: 22 jun. 2008. 